\title{
Interface
}

\section{IMAGENS NO ESPELHO DE VÊNUS: VIVÊNCIAS INCONSCIENTES}

\author{
Cleide Correia de Oliveira(1) \\ Camila Rodrigues Holanda Feitosa (2)
}

\begin{abstract}
Resumo: Os distúrbios psiquiátricos podem acometer os indivíduos em diversas fases de sua vida. Uma vez que a vulnerabilidade é agravada por eventos naturais somados a predisposição psicossocial e psicológica. A depressão trata-se de uma perturbação afetiva que culmina com um estado melancólico, mais que pode evoluir com alguns episódios de ansiedade que compartilha algumas características coma tristeza. As causas da maior parte das doenças de ordem psicológica não estão bem esclarecidas. Não existem causas isoladas da depressão, tratando-se assim de uma doença multifatorial, ou seja, não possui fatores causadores específicos que possam ser identificados dentro dos critérios de certeza absoluta científica. Quando surge imediatamente após o parto toma a designação de Depressão Pós-Parto. O estudo tem como objetivo Conhecer os fatores desencadeantes da Depressão Pós-Parto em gestantes no terceiro trimestre e puérperas do $1^{\circ}$ ao $3^{\circ}$ mês no PSF da cidade do Crato-Ce. Identificar os principais fatores de risco relacionados ao desenvolvimento da Depressão PósParto. A pesquisa e do tipo exploratório-descritivo, com abordagem qualitativa. A população constituiu-se por gestantes no terceiro trimestre de gestação e puérperas de qualquer idade obedecendo aos seguintes critérios de inclusão e exclusão. Para a obtenção de dados junto à amostra, utilizou-se uma entrevista semi-estruturada contendo perguntas abertas e fechadas. Concluímos que se faz necessário um planejamento das equipes para a execução de ações preventivas que proporcionem uma gestação e um puerpério emocionalmente sadios. Essas equipes devem atuar, fundamentalmente, no acompanhamento das mães puérperas atendendo às suas necessidades básicas de saúde e educação, bem como na orientação daquilo que se refere aos cuidados com a criança. Tais atitudes básicas não devem ser específicas da medicina em geral ou da psiquiatria em particular. Elas devem ser realizadas por equipes multiprofissionais da rede básica de saúde treinada para isso
\end{abstract}

Palavras chaves: Puérpera, Depressão pós- parto, 


\section{Introdução}

A gravidez e o parto representam momentos marcantes para a mulher. São períodos de grandes transformações, não só em seu organismo (envolvendo todos os sistemas fisiológicos), mas também em seu psiquismo e em seu papel sócio-familiar, portanto, a gestação e o puerpério são períodos da vida da mulher que precisam ser avaliados com especial atenção, pois envolvem inúmeras alterações físicas, hormonais, psíquicas e de inserção social, que podem refletir diretamente na saúde mental dos pacientes. Como é sabida, a pessoa têm, normalmente, uma maior probabilidade de adoecerem emocionalmente durante os momentos mais críticos de suas vidas, sejam momentos objetivamente tidos como bons ou ruins. Trata-se de uma resposta emocional às solicitações de adaptação.

Neste estado vulnerável a gestante precisa saber, de forma natural, sem sustos, que uma gravidez razoavelmente tranqüila terá uma importância considerável na estruturação física e emocional de seu bebe, assim como, no seu puerpério. Em certa medida a gestante necessita do apoio e carinho de todos, inclusive do setor de saúde.

A realização do pré-natal representa papel fundamental em termos de prevenção e/ou detecção precoce de patologias, tanto maternas quanto fetais, permitindo um desenvolvimento saudável do bebê e reduzindo os riscos da gestante. Informações sobre as diferentes vivências devem ser trocadas entre as mulheres e os profissionais de saúde, como: preparar a mulher para a maternidade, proporcionando informações educativas sobre o parto e o cuidado da criança, fazer prevenção, diagnóstico precoce e tratamento de doenças próprias da gestação ou que sejam intercorrências previsíveis dela, orientar psicologicamente a gestante para o enfrentamento da maternidade; dentre outras.

Essa possibilidade de intercâmbio de experiências e conhecimentos é considerada a melhor forma de promover a compreensão do processo de gestação e puerpério. Para algumas mulheres o início do puerpério pode significar também o início de transtornos e desequilíbrios emocionais, representando a adaptação do papel de mãe. Com o parto, ocorrem reações conscientes e inconscientes na puérpera e em todo o ambiente familiar e social imediato, que reativam profundas ansiedades. Uma das mais importantes é a revivência inconscientes da angústia do trauma do próprio nascimento: a passagem pelo canal de parto, que inviabiliza 
para sempre o retorno ao útero e empurra para um mundo totalmente novo e, portanto, temido.

O pós-parto é uma fase crítica para a mulher por causa das violentas mudanças nas taxas hormonais, além de todo o estresse que o parto implica. Verifica-se um aumento geral na incidência de distúrbios mentais nessa fase, principalmente para quem já sofreu algum problema psiquiátrico antes.

Em particular, da psicodinâmica da mulher durante o ciclo gravídico-puerperal, participam fatores hormonais e sócio-culturais, os quais conduzem os transtornos na área afetiva e intelectual e exigem a utilização de recursos que contribuirão para o desenvolvimento da personalidade do indivíduo e surgimento de um período de equilíbrio (TEDESCO, 1999).

Contudo, em diversas mulheres, a resposta de adaptação exigida pelo conflito transicional não é satisfatório, contribuindo para transtornos emocionais durante tais momentos. Nesse contexto, os principais fatores de risco para os distúrbios psíquicos no puerpério são a paridade (primíparas), a condição de mãe solteira, a morte perinatal, o parto cirúrgico, os antecedentes psiquiátricos maternos, história de distúrbios psiquiátricos prévios, as dificuldades de relação conjugal, circunstâncias sociais favoráveis, dentre outros.

O puerpério é um período marcado pela instabilidade emocional e vulnerabilidade feminina em relação às síndromes psiquiátricas no pós-parto. Uma das razões para esta realidade corresponde ao ritmo acelerado de mudanças na fase puerperal, associada às exigências culturais, sociais, familiares e pessoais em relação à puérpera, principalmente em relação ao desempenho das funções maternas adequadamente. $\mathrm{O}$ momento do término do puerpério é impreciso, aceitando-se em geral, que ele termina quando retorna a ovulação e a função reprodutiva da mulher.

Kaplan et. al. (1999), define os transtornos psíquicos puerperais como doenças mentais com início no primeiro ano após o parto e que se manifesta por desequilíbrios de humor psicóticos e não psicóticos. A etiologia das síndromes psíquicas pos parto envolve fatores orgânicos ou hormonais, psicossociais e predisposição feminina, deste modo, associação destes elementos possibilita o desenvolvimento do processo patológico.

A Depressão Pós-Parto é também, uma síndrome psiquiátrica importante e que acarreta uma série de conseqüências assim como a depressão em outra fase da vida da mulher. 
A maioria desses resultados repercute na interação mãe-filho e praticamente de forma negativa, na maioria das vezes. Além disso, promovem um desgaste progressivo na relação com os familiares e vida. Uma atuação adequada da saúde mental junto à questão da maternidade deve incluir o encorajamento e suporte para a mãe na lide com a criança e o envolvimento do pai e / ou outros membros da família nos cuidados à criança. Rutte (1991). Parte dessa atenção deve ser dirigida às dificuldades sociais e conjugais evolvidas na questão. Não obstante, outros estudos devem ser desenvolvidos para a elaboração de novos tipos de abordagens benéficas para a redução dos transtornos que comprometem a relação mãe-filho e, conseqüentemente, acabam comprometendo o desenvolvimento psíquico da criança.

Meu despertar pelo tema veio no decorrer da formação acadêmica, por se tratar de uma questão que diz respeito ao desenvolvimento psico-emocional das pessoas, portanto, um problema de saúde pública, a atenção à gravidez e ao período pós-parto que devem, sem dúvida, ser bastante considerada e principalmente a recordações de DPP em membro de minha família.

Assim, é importante que os profissionais de saúde desenvolvam ações preventivas na rede publica voltada não só para a saúde da gestante, mas para a mulher no geral. Além disso, estimular a compreensão da mulher em relação às fases críticas do puerpério, bem como noções e sentimentos provenientes deste período, ou seja, somando esforços na prevenção e tratamento da Depressão Pós-Parto que irão traduzir no exercício materno saudável e essencial ao desenvolvimento humano. (SANTOS et. al., 1997).

Nesse sentido, o trabalho desenvolvido tem ênfase na revisão de literatura acerca da Depressão Pós-Parto, um distúrbio psiquiátrico importante de ser diagnosticada e assistida a fim de assegurar um patamar satisfatório e realista no tocante à saúde do binômio mãe-filho atingindo a sua integralidade, ou seja, no âmbito social, físico e psicológico.

Para isso, na tentativa de atingir as principais dimensões da realidade investigada, este estudo tem como objetivos: Conhecer os fatores desencadeantes da Depressão Pós-Parto em gestantes no terceiro trimestre e puérperas do $1^{\circ}$ ao $3^{\circ}$ mês no PSF da cidade do Crato-Ce. Identificar os principais fatores de risco relacionados ao desenvolvimento da Depressão PósParto. 


\section{Método}

\section{Conhecendo o Cenário do Estudo}

Segundo Leopardi (2002) O investigador não escolhe o campo por acaso, ou seja, seu recorte em termos de espaço de investigação. Ao contrário, vai a este campo porque já possui uma questão ou um problema prático que deseja abordar, seja para conhecer suas características, seja para encontrar uma solução.

O cenário de estudo foi à busca ativa em PSF's da cidade do Crato-Ce, de gestantes com historia clínica prévia de distúrbios emocionais que possam a vim desenvolver Depressão Pós-Parto, assim como, puérperas que já estão acometidas pela Depressão Pós-Parto.

O Crato é um importante centro cultural e educacional. É um município de médio porte, com população marcadamente urbana com 83.917, e zona rural com 20.729 habitantes, totalizando 104.646 habitantes. Sua economia está assentada na agricultura e no comércio. O estudo foi desenvolvido durante os meses no período de Dezembro de 2006 a Fevereiro de 2007.

\section{Tipo do Estudo}

Para concretização da construção da pesquisa optamos por um estudo do tipo exploratório-descritivo. Leopardi (2002), explica que, a pesquisa exploratória "permite ao investigador aumentar a sua experiência em torno de um determinado problema, consiste em explorar tipicamente a primeira aproximação de um tema e visa criar a maior familiaridade em relação a um fato ou fenômeno.

O estudo é do tipo exploratório, pois se faz necessário um maior conhecimento a cerca da realidade em pauta, obtendo assim possíveis problemas de pesquisa e sugerir intervenções. Entretanto, a complexidade do trabalho se dará com a pesquisa descritiva. A pesquisa descritiva conforme definição de Leopardi (2002:120) "são estudos caracterizado pela necessidade de se explorar uma situação não conhecida, da qual se tem necessidade de maiores informações".

Leopardi (2002:116) em sua definição de pesquisa qualitativa é mais enfático ao dizer que: "a pesquisa qualitativa é apropriada se o interesse não esta focalizado em contar o numero de vezes em que a variável aparece, mais sim no que elas representam”. 
No que se refere à definição de pesquisa qualitativa de Minayo (1994:21) enfatiza que a pesquisa qualitativa se preocupa nas ciências sociais, com um nível de realidade que não pode ser quantificada e que responde a questões muito particulares.

\section{População e Amostra}

A população constituiu-se por gestantes no terceiro trimestre de gestação e puérperas de qualquer idade obedecendo aos seguintes critérios de inclusão e exclusão:

\section{Gestantes}

Critérios de inclusão: Realizar pré-natal no PSF da cidade do Crato; Estar no $3^{\circ}$ trimestre de gestação; Aceitar participar do estudo; Ter história prévia de Depressão PósParto; Multípara; Complicações gravídicas.

Critério de exclusão: Não aceitar participar da pesquisa; Não estar presente nos dias estabelecidos para as visitas.

\section{Puérperas}

Critério de inclusão: Realizado pré-natal no PSF da cidade do Crato; Estar entre o $1^{\circ}$ e o $3^{\circ}$ mês do pós-parto; Que tenha tido alguma complicação no parto;

Critério de exclusão: Não aceitar participar da pesquisa; Não estar presente nos dias estabelecidos para as visitas.

\section{Instrumento de Coleta de Dados}

Para a obtenção de dados junto à amostra, utilizou-se uma entrevista semi-estruturada contendo perguntas abertas e fechadas contendo as seguintes variáveis de características do sujeito: dados pessoais, familiares, informações gineco-obstétricas e possíveis fatores 
desencadeantes. A amostra será formada pelo total de 04 mulheres nas condições acima citadas atendidas pela Unidade de Saúde Básica .

Minayo (1994) define as entrevistas semi-estruturadas como um possível modo de trabalhar com a entrevista aberta ou não-estruturada, onde o informante aborda livremente o tema proposto, bem como as perguntas estruturadas previamente formuladas.

Para Haquette (1997), enquanto instrumento de coleta de dados, a entrevista, como qualquer outro instrumento, está submetido aos cânones do método científico, um dos quais é a busca da objetividade, ou seja, a tentativa de captação do real, sem contaminações indesejáveis nem da parte do pesquisador nem de outros fatores externos que possam modificar aquele real origina.

As entrevistas foram realizadas em locais reservados de forma individual, preferencialmente na Unidade de Saúde e em horário a ser marcado previamente.

Em relação aos aspectos étnicos, durante a realização da pesquisa, serão atendidas as exigências das Diretrizes e Normas da Pesquisa em Seres Humanos, apresentadas na Resolução 196/96 do Conselho Nacional de Saúde (CNS).

\section{Análise dos Dados}

A análise de dados utilizando-se a técnica de análise de conteúdo. Segundo Bardin (1997:38) a “Analise de conteúdo aparece como um conjunto de técnica de análise das comunicações, que utiliza procedimentos sistemáticos e objetivos de descrição do conteúdo das mensagens".

De acordo com Bardin (1997):

A análise de conteúdo desenvolve-se em três fases: 1- Pré-análise; 2Exploração do material; 3- Tratamento dos dados, inferência $e$ interpretação. (BARDIN, 1997:95).

A fase de organização inicia-se geralmente com os primeiros contatos com os documentos, é realizada uma leitura flutuante. A seguir, é realizada a escolha dos documentos e preparação do material para análise. 
A exploração constitui geralmente uma fase, que tem como objetivo administrar sistematicamente as decisões tomadas na pré-análise. Referem-se fundamentalmente as tarefas de condição envolvendo: o recorte (escolha das unidades), a enumeração (escolha das regras de contagem) e a classificação (escolha da categoria).

O tratamento de dados, a inferência e a interpretação, por fim, objetivam a tornar dados válidos e significativos.

\section{Conhecendo as imagens de Vênus...}

Durante as entrevistas buscou-se identificar os fatores predisponentes desencadeantes da Depressão Pós-Parto. A gestação e a maternidade são momentos esperados por todas as mulheres, traz imensa responsabilidade, já que se trata de uma nova vida e por isso requer bom preparo sócio-econômico e também psicológico.

Existem episódios na vida da mulher que são marcantes no seu desenvolvimento físico e que permitem também a oportunidade do desenvolvimento da sua personalidade. Conforme Cabral (2002) São períodos de transição, quando ocorrem profundas alterações no seu corpo, no seu papel social, nos seus relacionamentos interpessoais e na sua estrutura psíquica:São eles a menarcaadolescência, a gravidez e o clima-tério.

Todas estas situações são consideradas como críticas, pois serão responsáveis por um estado temporário de equilibrio instável devido às grandes perspectivas de mudanças, pontos decisivos no desenvolvimento emocional e que permitem restruturações, modificações e reintegrações da personalidade.

É, portanto, a gravidez, parte do processo normal do desenvolvimento $e$ requer reajustamento da mulher sob vários aspectos. Para abordá-los é importante levar em consideração a interação de algumas variáveis. (CABRAL, 2002: 13)

De acordo com as falas obtidas durante a entrevista, foram elaboradas as seguintes categorias: Categoria de numero um - Dificuldades adaptativas durante o período gestacional. Categoria de numero dois- Complicações gravídicas durante o período gestacional que levaram a algum comprometimento no puerpério.

A discussão das categorias foram subtraídas de acordo com as falas dos sujeitos. É importante ressaltar que houve uma dificuldade nesta coleta por parte de uma gestante e uma 
puérpera por se encontrarem em estado de perturbação afetiva avançada, porém, obtivemos ajuda das mães das respectivas.

- Categoria de numero um - Dificuldades adaptativas durante o período gestacional.

Quando questionadas a respeito de alguma dificuldade adaptativa durante o período gestacional, obtivemos os seguintes depoimentos:

(...) ela teve muito medo quando estava grávida, porque ela sangrou e seu namorado tinha largado ela, ela fumava muito e bebia... (relato segundo sua mãe) DAPG

(...) a primeira gravidez dela foi ótima, vivia andando na rua. Quando ela engravidou de novo o marido dela saiu de casa, ai ela ta nessa tristeza, não conversa, não come, não vai para o posto e nem toma os remédios que o medico passou (...) (relato segundo sua mãe). DAPG

Observa-se pela fala acima que a gravidez foi afetada com a saída do companheiro, alterando um período de adaptação da mulher com várias mudanças ocorrendo em seu organismo, tanto fisiológicos com psicológicos e sociais. È de suma importância que durante o período de gravidez o casal começa a preparar-se para o seu novo papel como pais. Não só cada indivíduo deve adquirir consciência em sua função, e consciência de si próprio exercendo essa responsabilidade, como deve também reordenar a percepção do parceiro para incluir o novo desempenho com a chegada de um filho. Assim uma mulher grávida pela primeira vez deve não só adquirir o papel de mãe, como também começar a interagir com seu companheiro como pai, como marido, como amante e assim por diante. A gestação traz consigo, normalmente, significativas mudanças familiares em conseqüência da preparação para o nascimento de um novo membro (ZIEGEL, 1986).

Sentir a gravidez acarreta normalmente muita responsabilidade e disponibilidade emocional. É comum quem sente a gravidez conseguir ter um trabalho de parto mais fácil, por se entregar mais e consequentemente entrar mais preparada na maternidade.( ZIEGEL, 1986); RODRIGUES, 2003). A gravidez causa também efeito sobre o pai, e para o autor,

O comprometimento biológico do pai com a gravidez termina com a concepção. Seu comprometimento social e psicológico depende em grande parte de seu relacionamento com a mãe (...), a experiência do homem com a gravidez é intrinsecamente diferente daquela da mulher, contudo, existem muitas semelhanças quando o casal compartilha a gravidez e planeja em conjunto a paternidade. (ZIEGEL, 1986:222) 
Podemos imaginar o parto como uma janelinha que se abre sobre a vida íntima de uma mulher. "Através da lente de seu parto podemos saber como ela se vê, qual é a relação com o seu corpo, sua postura no mundo frente aos poderes e autoridades, o parto é revelador" (...). "Ele aglutina em si inúmeros sentidos e perspectivas. Sendo um momento tão natural e espontâneo, ele também é rico em cultura, autoconhecimento, filosofia de vida e espiritualidade. (RODRIGUES, 2003:6)

Vejamos as falas a seguir:

(...) não tive nenhum problema na gravidez, apesar de não ter engravidado de propósito, mais também já tava no tempo, pois já tenho 24 anos(...) $D A P G$

(...) não quis engravidar, porque eu perdi duas crianças tive medo de sofrer de novo, ainda não me acostumei com essa barriga, por isso eu fumo para passar o tempo(...) DAPG

Entendemos pelas falas obtidas que uma relação não harmoniosa, bem como o não planejamento da gravidez são fatores relevantes para que a gestante possa sofrer alterações nas sensações psicológicas, assim também como a predisposição representa uma parcela considerável na etiologia dos transtornos psiquiátricos puerperais.

O processo de maternidade baseia-se em um vínculo recíproco entre mãe e filho que se fortalece e se concretiza ao nascimento, com a troca de olhares, carinho, a tomado ao seio, o toque, gestos e atos de proteção, trazendo ao recém-nascido segurança e aconchego, promovendo um maior vínculo de sentimentos de realização como mãe. Mãe e bebê sentem-se seguros e já estabelecem uma relação de confiança mútua para os próximos desafios de sobrevivência. (RODRIGUES, 2003)

O modo como a gestante age durante a gravidez, pode ser influenciado pelo seu estilo de vida e também pode ser afetado pela cultura da mesma. A aceitação da gravidez e em seguida aceitação da criança e principalmente a aceitação do seu papel de mãe, são alguns dos objetivos que devem ser alcançados pela futura mamãe, durante os nove meses de gravidez. (ZIEGEL, 1986)

- Categoria número dois- Complicações gravídicas durante o período gestacional que levaram a algum comprometimento no puerpério.

Um ponto importante é o sentimento da gestante em relação ao parto. Rodrigues (2003) esclarece: Quando um ser humano feminino se vê no centro do palco - colocar para fora de si alguém que gerou, formou, alimentou e está pronto para vir ao mundo - sente uma 
dor emocional profunda. (...) e relaxa seu corpo, entregando-se às próprias sensações, entra em trabalho de parto. É fantástico. É maravilhoso. É totalmente borbulhante transformar uma dor desconhecida, jamais sentida, no mais intenso de todos os prazeres. (RODRIGUES, 2003:5)

O período de transição determinado pela vinda do filho não termina com o parto. Como afirma Cabral (2002), que na realidade grande parte das mudanças que determinam o amadurecimento ocorrem após o parto, devendo o puerpério ser considerado como continuação da situação de transformação, implicando novas mudanças fisiológicas, agora de maneira mais abrupta do que as que lentamente instalam-se na gravidez, e também modificações na rotina e no relacionamento familiar, assim como na consolidação do relacionamento entre pais e filho(s).

No que se refere a comprometimento no puerpério obtivemos os seguintes depoimentos:

(...) ela não quer conversar com ninguém, nem sair do quarto, eu já tentei levar ela para o hospital mais ela não quer (... ) (segundo relato da mãe). CGPP

(...) tive crises de choro, não conseguia dormir pensando e meu filho estava bem, eu nunca conseguia ficar tranqüila. Ai meu marido notou e perguntou por que eu chorava tanto (...) CGPP

Segundo relatos à cima podemos constatar que a Depressão Pós-Parto pode ter inicio insidiosa, e que se ela for diagnosticada cedo seu prognóstico será bem melhor. Por isso é importante ressaltar que a realização do pré-natal representa papel fundamental em termos de prevenção e/ou detecção precoce de patologias, reduzindo os ricos da gestante.

Sabe-se que tanto a gravidez como o parto são eventos psicossociais, agindo assim profundamente nas vidas dos pais e também das famílias. Dessa maneira afirma Branden (2000), nada é mais definitivo para o auto-conceito de alguns homens e mulheres do que o desafio de gerar e criar um filho. As alterações fisiológicas e psicossociais ajudam a mulher a adaptar-se à gravidez, manter sua saúde durante toda a gestação e preparar-se para o nascimento de seu filho.

As modificações fisiológicas associadas à gravidez tanto podem ocorrer de forma sutil como podem ser bastante marcante. Essas alterações embora sejam normais e necessárias, podem também ser extremamente desconfortáveis, e estas são explicadas fisiologicamente devido ao aumento dos hormônios progesterona e estrogênio, no corpo fecundado, mas a 
forma como a mulher aceita os sintomas desde o princípio e aprende a lidar com eles, vai ser de fundamental importância para o perfeito andamento da gravidez e consequentemente do parto. (BRANDEN, 2000; RODRIGUES, 2003)

Confirma Rodrigues (2003) que durante o período de gestação ocorrem muitas mudanças que exigem da mulher grávida uma adaptação a essa nova forma de ser e estar no mundo, sendo que às vezes o fator psicológico não dá conta de receber e aceitar as transformações, pelas quais o corpo físico possa estar passando. É extremamente importante essa aceitação, para que sua saúde seja mantida durante toda a gestação.

Para que a gestante possa ser assistida adequadamente, é necessário que os profissionais de saúde compreendam as alterações fisiológicas normais e como estas afetarão a paciente. Segundo Branden (2000), as alterações fisiológicas que ajudam a diagnosticar a gravidez representam apenas uma pequena parte das modificações que ocorrem na gestante. À medida que o feto cresce e o perfil hormonal se modifica, o corpo da mulher passa por adaptações fisiológicas em todos os sistemas do organismo, visando principalmente a adaptação ao feto e a preparação para o nascimento do bebê. (BRANDEN, 2000:34).

\section{Considerações finais}

A depressão é um estado comum, em muitas situações da vida, e todas as pessoas, em algum momento, se sentem deprimidas. Mas a depressão torna-se desproporcional quanto à intensidade e duração, tornando-se, muitas vezes, incontrolável necessitando, portanto, de algum tipo de assistência. Antes de examinar a depressão como um fator que esteja afetando desfavoravelmente e incapacitando as relações interpessoais, principalmente durante o período puerperal, precisa-se saber reconhecer seus sintomas, partindo de um conhecimento prévio específico na área de psiquiatria e saúde mental.

No sentido de fornecer informações, a respeito do estado emocional que atinge grande parte das mulheres no pós-parto, tais informações tornam-se necessárias para que a puérpera possa evitar que uma reação normal se transforme e atinja níveis patológicos, visto que os primeiros dias após o parto são carregados de emoções intensas e variadas. É uma alternativa seria conseguir o maior numero de informações adequadas, de como amenizar os efeitos da depressão pós-parto. 
$\mathrm{Na}$ tentativa de prevenção desses distúrbios, poderia ser estabelecida, como rotina da unidade de saúde, tanto durante a gestação como no período puerperal, a busca dos fatores de risco através de entrevistas semi-estruturadas, ou até mesmo com conversas informais para, a partir de então, fornecer apoio, principalmente por parte da equipe de enfermagem e da família devido o contato mais prolongado dessas pessoas com a parturiente/puérpera e, caso necessário, de um psicólogo ou psiquiatra e assistente social, para evitar complicações futuras como infanticídio, homicídio e suicídio.

\section{Referências}

BARDIN, L. Análise de conteúdo. Lisboa - Portugal: Setenta, 1997.

BRANDEN, P, e S. Enfermagem materno-infantil. 2 ed. Rio de Janeiro: Reichmann \& Affonso, 2000.

GIL, Antonio Carlos. Métodos e técnicas de pesquisa social. $4^{\mathrm{a}}$ Edição. São Paulo: Atlas S.A., 1995.

. Como Elaborar Projetos de Pesquisa. $4^{\circ}$ ed. Editora Atlas.In: Antonio Carlos Gil. Métodos e Técnicas de Pesquisa Social. 5 ed. São Paulo. Atlas S. A., 1999.

HAGUETTE, T. M. Metodologias qualitativas na sociologia. 5. ed. Petrópolis: Vozes, 1997.

KAPLAN, H.I.; SADOCK, B.J. Tratado de psiquiatria. $6^{\circ}$ ed. Porto Alegre: Artmed, 1999.

LEOPARDI, M. T. Metodologia da pesquisa na saúde. 2 ed. Florianópolis: UFCS - Pós Graduação em Enfermagem.

MINAYO, M. C. S. (org) Pesquisa social: teoria, método e criatividade. 20 ed. Petrópolis RJ: Vozes, 2002.

. M. C. S. et al. Pesquisa social: técnica, método e criatividade. $13^{a}$ Edição.

Petrópolis : Vozes, 1999.

RODRIGUES, C. Sintomas-mestre, os doutores emocionais [on line]. Disponível em: $<$ www.amigasdoparto.com.br>. Acessado em 27 de março de 2003.

SANTOS, M. F.; Martins, F. C., Pasquali, L. São Paulo: Lemos. 2002.

ZAGONEL, Ivete Palmeira Z. Consulta de Enfermagem: um modelo de metodologia para o cuidado. In: WESTPHALEN, Mary E. A.; CARRARO, Telma Elisa. Metodologias Para 
a Assistência de Enfermagem: teorizações, modelos e subsídios para a prática. Goiânia: AB editora, 2001.

(1) Cleide Correia de Oliveira é Enfermeira, Professora Ms. da Universidade Regional do Cariri - URCA. E-mail: cleidecorreia27@hotmail.com;

(2) Camila Rodrigues Holanda Feitosa é Enfermeira na Região do cariri Cearense.

E-mail: camilarfeitosa@hotmail.com. 